\title{
Biasing power law exponents by magnitude estimation instructions
}

\author{
GEORGE H. ROBINSON \\ University of North Alabama, Florence, Alabama 35630
}

\begin{abstract}
Different sets of magnitude estimation instructions were given to different subjects in order to see if this could account for the reported variation of the exponent in Stevens' power law. Subjects who were asked to give as an estimate of pulse rate (Experiment I) or loudness (Experiment II) the number 50 when it was $1 / 2$ of the standard and 150 when it was $11 / 2$ times the standard yielded exponents which were reliably smaller than those obtained when subjects were asked to respond with 25 when it was $1 / 4$ of the standard and 750 when it was $7^{1 / 2}$ times the standard. For the condition generating the larger exponent in each experiment, a power law relationship fits the data better than Fechner's law. Both experiments were exactly replicated for comparison, with the same results obtained as mentioned above. The frequently observed variability of the exponent may be a consequence of bias introduced by numerical examples as part of the instructions in a magnitude estimation task.
\end{abstract}

S. S. Stevens (1970) suggests that the numerical magnitude of the exponent in his psychophysical power law may be a relatively simple fractional value. This magnitude of the exponent would represent characteristics of the sensory transducer for the modality involved (S. S. Stevens, 1961). There are, however, difficulties in finding out for a particular sense modality what the "true" exponent is. One difficulty is that exponents based on groups of subjects vary from one experimental situation to the next (Macmillan, Moschetto, Bialostozky, \& Engel, 1974; Marks, 1974). A second problem is that there is variation in individual exponents derived under the same conditions (Jones \& Marcus, 1961; Luce, 1972; Marks \& Cain, 1972; Marks \& J. C. Stevens, 1966; Pradhan \& Hoffman, 1963; J. C. Stevens \& Guirao, 1964). It would appear that if the power law is correct, then the obtained exponent might be determined by several possible factors, including not only those involved in sensory transduction as suggested by $\mathbf{S}$. S. Stevens (1961), but also biases that would result from perceptual differences, response habits, and biases contributed by the particular experimental situation.

The presence of nonsensory biases in magnitude estimation has been indicated by several investigations. Jones and Marcus (1961) determined individual exponents for the modalities of weight, taste, and smell for subjects who gave estimates of each of the three types of stimulation. An analysis of variance revealed that in addition to a reliable modality difference in exponent there was a significant main effect for subjects. This latter finding led them to suggest a modification of the power law from $\mathbf{R}=\mathrm{aS}^{\mathrm{b}}$ to $\mathrm{R}=\mathrm{aS}^{\mathrm{bc}} \mathbf{i}$, where $\mathrm{c}_{\mathrm{i}}$ is a constant characteristic of the individual subject. Whether the particular value of $c_{i}$ for a given subject was based on perceptual factors or on the subject's response habits, including his use of numbers, was not answered. In a subsequent investigation, Jones and Woskow (1962) found a statistically significant positive correlation between exponents for loudness estimation and range of numbers used a week earlier by the same subjects in pitch estimation. This suggests that a response bias may be operating in individual subjects and would account for the "personal exponent" of Jones and Marcus (1961).

Similarly, Rule, in a series of investigations, has found reliable positive correlations between exponents for pairs of continua when the same subjects gave magnitude estimates of circle size, numerousness, and line length with a standard (Rule, 1966), of circle size and proportion with a standard (Rule, 1968), and of circle size, numerousness, and line length without a standard (Rule, 1969). The within-subject consistency was attributed to the subjects' use of the number system.

With regard to the use of numbers, Beck and Shaw (1965) found that loudness judgments may be affected by the numerical value of the standard and its magnitude. In the second part of their investigation, the subjects were given more extensive instructions to minimize biases. One of the differences between these more extensive instructions and those in the first part of the study was the providing of very large and very small numbers $(100,000$ and .00001$)$ corresponding to very large and very small stimulus ratios. The resulting slopes, which represent the exponents, were observed to be steeper than those in the first part of the study. Since other parts of the instructions were also changed, it is not possible to identify the basis for the change in slope.

The possibility exists that the numerical examples given to the subject in a magnitude estimation task could affect the obtained exponent. The present investigation was done in order to determine if such an effect would occur in two magnitude estimation 
tasks: pulse rate estimation (Experiment I) and loudness estimation (Experiment II).

\section{EXPERIMENT I}

\section{Method}

Subjects. Students in two sections of an introductory psychology course were subjects for Experiment I and its replication.

Apparatus. A unijunction transistor (UJT) oscillator generated 1 -msec pulses which were amplified and delivered to a speaker. As a rough index, the sound level measured $30 \mathrm{~cm}$ in front of the speaker with a General Radio 1563 sound-level meter was $59 \mathrm{~dB}(\mathrm{~A})$ for the reference frequency $(7.494 \mathrm{pps})$. Switch-selected pulse frequencies used were measured with a frequency counter.

Procedure. The experimental sessions were conducted in a classroom setting. The oscillator, amplifier, and speaker were interconnected and turned on with the reference frequency initially presented continuously. Following this, all subjects in the class were given a combined instructions and data sheet on which appeared one or the other of two sets of instructions followed by 10 spaces for responses to the 10 trials described below. These sheets containing instructions were given out in the sequence $\mathrm{ABABAB} \ldots$ so that every successive subject received a set differing from that received by subjects in front of and behind him. As the instructions were distributed, the experimenter vocally asked the subjects to read the instructions and stated that no questions could be answered. No mention was made of any difference in instructions.

Instructions A $(1 / 2-11 / 2)$ were the following: "As you read this you are hearing a series of pulses of a constant frequency. For this experiment assign the number 100 to this frequency which will be called the Reference Frequency. It will be present between each trial. I am going to present you with a number of Comparison Pulse Frequencies with one occurring on each of the following 10 trials. Your task will be to try to estimate the frequency of each Comparison Pulse Frequency relative to the Reference Frequency you now hear. For example, if on a particular trial the Comparison Pulse Frequency seems $1 \frac{1}{2}$ times the Reference Frequency, assign the number 150 to it: if it is $1 / 2$ the Reference Frequency, assign the number 50 to it. If you do not understand the instructions or if you prefer not to participate, simply place an $X$ in the space for each response estimate. Do not put your name on this sheet. Try to be as accurate as you can."

Instructions B $(1 / 4-71 / 2)$ were identical in wording and word position to Instructions A except that the numbers $1 \frac{1 / 2}{2} 150,1 / 2$, and 50 were replaced by $71 / 2,750,1 / 4$, and 25 , respectively. The particular numbers used in the two sets of instructions were selected on the bas is of similarity in order to minimize the possibility that the subjects would become aware of the separate instructions.

After all subjects had completed reading the instructions, 10 trials were given with a 10 -sec presentation of the comparison frequency given on each trial. During the intertrial interval of approximately $20 \mathrm{sec}$, the experimenter announced the number of the next trial and selected the comparison frequency for the next trial. The comparison frequencies used were $2.720,1.662$. 23.426, 4.198, 6.823. 3.069. $18.748,31.542,8.630$, and 14.713 pps for the 10 trials, respectively. The sequence of frequencies was random, and the reference trequency was 7.494 pps. Subjects returned the combined instructions and data sheets immediately after completion of the 10 th trial and were asked not to talk about the experiment outside of class.

The replication of Experiment I was done exactly as the initial experiment but with another class of introductory psychology students later the same day in the same classroom. The request not to talk about the experiment outside of class was omitted in the replication.

\section{Results}

Seven of a total of 51 students in the classroom during the initial experiment or its replication omitted

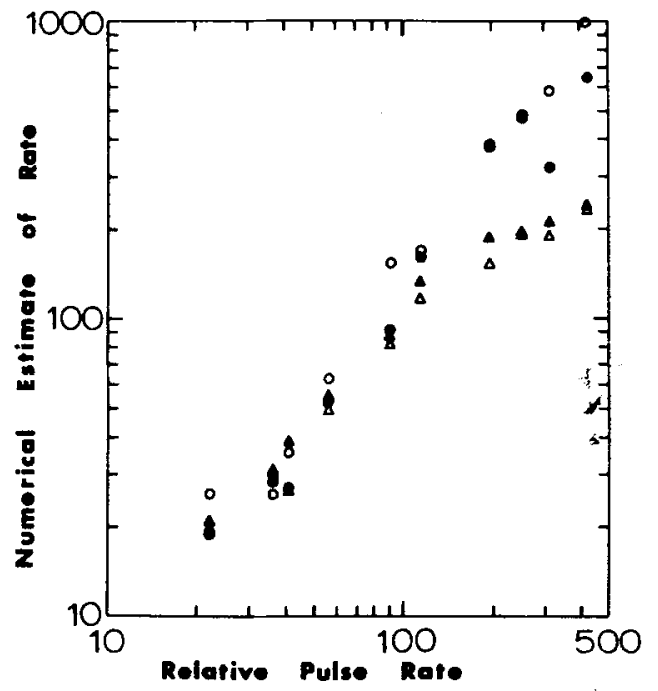

Figure 1. Geometric mean numerical estimate of relative pulse rate as a function of relative pulse rate. The reference frequency, or standard, was assigned a numerical value of 100 , while comparison frequencies were higher or bwer. Triangles represent results under instructions, which included, as examples, suggested comparison frequencies of $1 / 2$ and $1 \frac{1}{2}$ times the reference frequency. Circles represent, correspondingly, instructional examples of $1 / 4$ and $71 / 2$ times the reference frequency. Filled symbols show results from the initial experiment, and open symbols represent the exact replication. Although some ordinate values are very close to others, there are four ordinate values for each value of the abscissa.

responses to one or more of the 10 trials and were, consequently, eliminated from the analysis, which is based on the remaining 44 subjects.

Figure 1 shows a $\log$-log plot of geometric mean numerical estimates of relative pulse rate as a function of relative pulse rate for each set of instructions and for the initial experiment and its replication. The relative pulse rate, $S$, is the comparison frequency given as a percentage of the reference frequency. Best fitting equations of the form $R=a S^{n}$ for each of the four sets of data were computed by the method of least squares on the equation $\log R=\log a+n \log S$. These results are presented in Table 1 . As can be seen

Table 1

Pulse Rate Power Law Parameters for Best-Fitting Equation $R=a^{n}$ (Based on Geometric Means)

\begin{tabular}{|c|c|c|c|c|}
\hline & $\mathbf{N}$ & $\mathbf{a}$ & $\mathrm{n}$ & $r^{2}$ \\
\hline & \multicolumn{4}{|c|}{ Instructions $A\left(1 / 2-1 \frac{1}{2}\right)$} \\
\hline $\begin{array}{l}\text { Initial } \\
\text { Experiment } \\
\text { Replication }\end{array}$ & $\begin{array}{r}14 \\
6\end{array}$ & $\begin{array}{l}1.57 \\
1.26\end{array}$ & $\begin{array}{l}.871 \\
.893\end{array}$ & $\begin{array}{l}.968 \\
.967\end{array}$ \\
\hline & \multicolumn{4}{|c|}{ Instructions B $(1 / 4-71 / 2)$} \\
\hline $\begin{array}{l}\text { Initial } \\
\text { Experiment } \\
\text { Replication }\end{array}$ & $\begin{array}{r}17 \\
7\end{array}$ & $\begin{array}{l}.298 \\
.314\end{array}$ & $\begin{array}{l}1.29 \\
1.33\end{array}$ & $\begin{array}{l}.967 \\
.984\end{array}$ \\
\hline
\end{tabular}

Note. $N$ is the number of subjects in each condition, and the coefficient of determination, $r^{2}$, provides a measure of the strength of linear association between the logarithms of the geometric mean estimates and logarithms of relative pulse rates. 
Table 2

Mean Power Law and Fechner's Law Values of $r^{2}$ (Pulse Rate Estimation)

\begin{tabular}{|c|c|c|c|c|c|}
\hline & $\begin{array}{c}\text { Power } \\
\text { Law }\end{array}$ & $\begin{array}{l}\text { Fechner's } \\
\text { Law }\end{array}$ & df & $\mathrm{t}$ & $\mathrm{p}$ \\
\hline \multirow{3}{*}{$\begin{array}{l}\text { Initial } \\
\text { Experiment } \\
\text { Replication }\end{array}$} & \multicolumn{5}{|c|}{ Instructions $A(1 / 2-11 / 2)$} \\
\hline & $\begin{array}{l}.915 \\
.880\end{array}$ & $\begin{array}{l}.932 \\
.879\end{array}$ & $\begin{array}{r}13 \\
5\end{array}$ & $\begin{array}{r}-1.14 \\
.05\end{array}$ & $\begin{array}{l}>.2 \\
>.8\end{array}$ \\
\hline & \multicolumn{5}{|c|}{ Instructions $B(1 / 4-71 / 2)$} \\
\hline $\begin{array}{l}\text { Initial } \\
\text { Experiment } \\
\text { Replication }\end{array}$ & $\begin{array}{l}.898 \\
.866\end{array}$ & $\begin{array}{l}.756 \\
.698\end{array}$ & $\begin{array}{r}16 \\
6\end{array}$ & $\begin{array}{l}7.02 \\
4.28\end{array}$ & $\begin{array}{l}<.00001 \\
<.01\end{array}$ \\
\hline
\end{tabular}

from Table 1, the exponents for the initial experiment and the replication are larger under the condition of Instructions $B(1 / 4-71 / 2)$.

In order to determine the reliability of the difference in exponents between the two instructional conditions, the best fitting equation $\mathrm{R}=a S^{\mathrm{n}}$ was computed by the method of least squares for each individual subject. For the initial experiment, the mean exponent (and $95 \%$ confidence interval) for the Instructions A $\left(1 / 2-1 \frac{1}{2}\right)$ condition was 0.871 $(0.749-0.993)$ and for the Instructions B $(1 / 4-71 / 2)$ condition was $1.29(1.17 \cdot 1.41)$. This difference between means when tested with a two-tail $t$ test is significant, $t(29)=5.14, p<.0001$. Similarly, for the replication, the mean exponent (and $95 \% \mathrm{Cl}$ ) was $0.893(0.615-1.17)$ for the Instructions $A$ condition and $1.33(1.19-1.46)$ for the Instructions B condition. This difference was also significant, $t(11)=3.76$, $\mathrm{p}<.005$.

In order to compare the fit of the data with Stevens' power law and with Fechner's law, two Pearson product moment correlation coefficients were computed for each subject. Power law correlations between log numerical estimates and log relative pulse rates and Fechner's law correlations between numerical estimates and log relative pulse rates were each squared to give two coefficients of determination for each subject. Mean coefficients of determination for each law were compared by two-tail $t$ tests for correlated measures. These results are given in Table 2. For the Instructions A condition, neither the initial experiment nor the replication yielded a significant difference. Stevens' power law fits significantly better in both, however, under the Instructions B condition.

\section{EXPERIMENT II}

\section{Method}

Subjects. Students in two sections of an introductory psychology course during the semester subsequent to that of Experiment I were used for Experiment II and its replication. No subjects of Experiment II had participated in Experiment I.

Apparatus. A bistable multivibrator driven by a UJT oscillator provided a $926-\mathrm{Hz}$ square wave which was passed through an attenuator to a small power amplifier driving a speaker. Relative voltages across the speaker were measured with a Hewlett-Packard 400D VTVM. A General Radio 1563 sound-level meter positioned $30 \mathrm{~cm}$ in front of the speaker in the classroom when no students were present indicated sound levels in $\mathrm{dB}(\mathrm{A})$ units which correlated +.999 with relative sound levels in $\mathrm{dB}$ calculated on the basis of VTVM-measured voltages across the speaker.

Procedure. In general, the procedure for Experiment II was the same as that for Experiment I. Instructions $A$ and $B$ were identical to those in Experiment I except for the replacement of "frequency" and "pulse frequencies" by "loudness" and "loudnesses," respectively.

The comparison loudnesses were generated by the following random sequence of speaker voltages for the 10 trials: $0.063,0.400$. $1.32,0.150,0.335,1.00,0.0228,0.128,0.733$, and $0.571 \mathrm{~V}$. The reference loudness was generated by $0.203 \mathrm{~V}$, which corresponded to a sound level of $78 \mathrm{~dB}(\mathrm{~A}) 30 \mathrm{~cm}$ from the speaker.

\section{Results}

Twelve of a total of 63 students present in the classroom during the initial experiment or its replication either omitted responses or gave an estimate of zero to one or more of the 10 trials or (in two subjects) gave estimates exceeding 100 to the lowest or less than 100 to the highest comparison loudness (suggesting failure to understand the instructions) and were, consequently, eliminated from the analysis, which is based on the, remaining 51 subjects.

Figure 2 gives a $\log$-log plot of geometric mean numerical estimates of relative loudness as a function of relative amplitude expressed in decibels relative to the standard or reference loudness. The relative amplitude, $S$, of the voltage across the speaker for each comparison loudness expressed as a percentage of that generating the reference loudness was used in determining the parameters of the best fitting equation $\mathrm{R}=a S^{\mathrm{n}}$ by least squares. These results are presented in Table 3 . The exponent in both the initial experiment and replication is larger for the Instructions B $(1 / 4-71 / 2)$ condition.

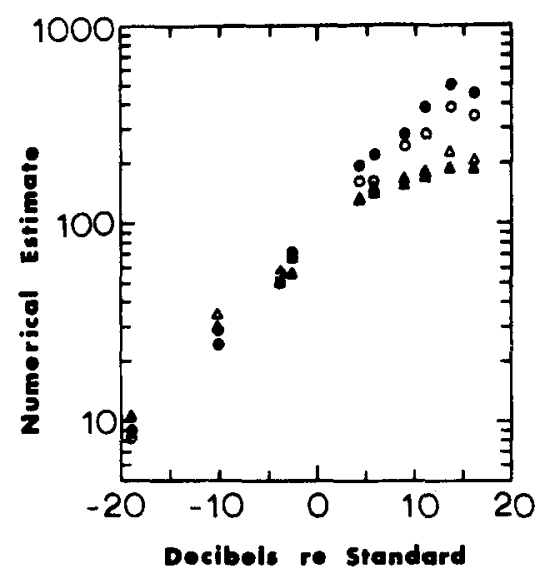

Figure 2. Geometric mean numerical estimates of relative loudness as a function of signal amplitude. The reference loudness, or standard, was assigned a numerical value of 100 , while comparison loudnesses were amplitudes above or below. The abscissa covers an amplitude range from 10 to 1,000 . Filled and open symbols have meanings equivalent to those in Figure 1. 
Table 3

Loudness Power Law Parameters for Best-Fitting Equation $\mathrm{R}=\operatorname{aS}^{n}$ (Based on Geometric Means)

\begin{tabular}{lcccc}
\hline & $\mathrm{N}$ & $\mathrm{a}$ & $\mathrm{n}$ & $\mathrm{r}^{2}$ \\
\hline & & \multicolumn{3}{l}{ Instructions A $\left(1 / 2-1^{1 / 2}\right)$} \\
Initial & 12 & 2.30 & .729 & .958 \\
Experiment & 13 & 2.06 & .768 & .946 \\
Replication & & \multicolumn{2}{l}{ Instructions B $(1 / 4-71 / 2)$} & \\
& & .774 & 1.039 & .986 \\
Initial & 15 & .997 & .955 & .984 \\
Experiment & 11 & & & \\
Replication & & &
\end{tabular}

Note. $N$ is the number of subjects in each condition, and $r^{2}$ is the coefficient of determination.

As was done in Experiment 1 , least squares solutions for the equation $\mathrm{R}=\mathrm{aS}^{\mathrm{n}}$ were determined for each individual subject. For the initial experiment, the mean exponent (and $95 \%$ CI) for the Instructions $A\left(1 / 2-1 \frac{11 / 2}{}\right)$ condition was 0.729 $(0.603-0.856)$ and for the Instructions $B(1 / 4-71 / 2)$ condition was $1.039(0.885-1.193)$. The difference between means is significant, $\mathrm{t}(25)=3.24, \mathrm{p}<.005$. For the replication. the mean exponent (and 95\% CI) for the Instructions $A$ condition was 0.768 (0.667-0.869) and for the Instructions B condition was $0.955(0.828-1.082)$. This difference between means is also significant, $\mathrm{t}(22)=2.58, \mathrm{p}<.02$. Thus, as in Experiment 1 , the Instructions $B$ condition generated the larger exponent.

As in Experiment I, a comparison of the fit of Stevens 'power law and Fechner's law to the data was made by computing coefficients of determination between $\log$ numerical estimates and $\log$ relative amplitudes (power law) and between numerical estimates and log relative amplitudes (Fechner's law) for each subject. Mean coefficients of determination were compared by two-tail t tests for correlated measures. These results are given in Table 4 . Neither the initial experiment nor the replication for the Instructions A condition gave a significant difference. For the Instructions B condition, the power law fits signiticantly better than Fechner's law in both the initial experiment and its replication.

\section{DISCUSSION}

In both pulse rate estimation and loudness estimation, the magnitude of the exponent has been found to be affected by the range of numerical examples included as part of the instructions. For the numerical examples generating the larger exponents, the power law was found to tit the data better than Fechner's law. For the smaller exponents, no detectable difference in goodness of fit between the two law's was found, a finding which is consistent with observations of others when working with modalities yielding smaller exponents (Uttal, 1973, p. 265).

In view of the finding that the size of the exponent is affected by the instructions given to the subjects, it is not clear what significance there is to comparing the exponents of the present investigation with those of others. J. C. Stevens and Shickman (1959) found that magnitude estimation of repetition rates of various stimuli increased with approximately the 1.0 power of the stimulus rate. This value is near the exponent of 1.1 that one obtains by averaging the four separate exponents obtained here. This similarity, however, seems to be more coincidental than anything etse. The loudness exponents obtained in the present study tend to be larger than those found by others using magnitude estimation (Marks, 1974). The reason for this is not clear.

The variability within each condition for the current experiments was not as great as had been feared as a consequence of conducting the experiments in a classroom setting. The mean standard deviation for the loudness estimation exponents obtained here was 0.208 , which is not much greater than the value of 0.19 obtained from individual subjects wearing earphones in a soundproofed room reported by J. C. Stevens and Guirao (1964). J. C. Stevens and Shickman (1959) do not provide information about variability of the exponent across subjects in their repetition estimation investigation.

The finding that the obtained exponent depends upon the instructions in a magnitude estimation task indicates that this type of task is not likely to provide us with the true value of the exponent that $S$. S. Stevens (1970) sought. The equation proposed by Jones and Marcus (1961) may need to be modified from $R=a S^{b c_{i}}$ to $R=a S^{b c_{i} d_{j}}$, where $b$ is the transducer-determined portion of the exponent, $c_{i}$ is a relatively stable constant for the individual across sense modalities, and $d_{j}$ is specific to the instructional conditions in a particular experiment or situation. The major contributor to the observed variability of the exponent across experiments would likely be $d_{j}$, but stable response habits (including number usage) would require an individual difference variable represented here by $c_{i}$. That such an additional variable is needed is suggested by the results of Jones and Marcus (1961), Jones and Woskow (1962), and Rule (1966, 1968, 1969).

Table 4

Mean Power Law and Fechner's Law Values of $r^{2}$ (Loudness Estimation)

\begin{tabular}{lccccc}
\hline & $\begin{array}{c}\text { Power } \\
\text { Law }\end{array}$ & $\begin{array}{c}\text { Fechner's } \\
\text { Law }\end{array}$ & df & $\mathrm{t}$ & $\mathrm{p}$ \\
\hline Initial & \multicolumn{5}{c}{ Instructions A $\left(1 / 2-1 \frac{1}{2}\right)$} \\
Experiment & .836 & .857 & 11 & -.70 & $>.5$ \\
Replication & .909 & .904 & 12 & .33 & $>.5$ \\
Initial & \multicolumn{5}{c}{ Instructions B $(1 / 4-71 / 2)$} \\
Experiment & .926 & .758 & 14 & 5.39 & $<.0001$ \\
Replication & .912 & .764 & 10 & 4.53 & $<.002$ \\
\hline
\end{tabular}


Several investigators have attempted experimentally to separate the hypothetical two factors which constitute the sensory or input portion and the response or output portion of the exponent (Curtis, 1970; Curtis, Attneave, \& Harrington, 1968; Duda, 1975). The present investigation reveals one source of bias which appears to contribute to the output portion of the exponent.

\section{REFERENCES}

BECK. J.. \& SHAw. W. A. Magnitude of the standard. numerical value of the standard. and stimulus spacing in the estimation of loudness. Perceptual and Motor Skills. 1965. 21. 151-156.

Curris. D. W. Magnitude estimations and category judgments of brightness intervals: A two-stage interpretation. Journal of Experimental Psychology, 1970. 83. 201-208.

Curtis. D. W.. Attneave, F., \& Harrington. T. L. A test of a two-stage model of magnitude judgment. Perception \& Psychophysics. 1968. 3. 25-31.

DudA. P. D. Tests of the psychological meaning of the power law. Journal of Experimental Psychology: Human Perception and Pertormance, 1975. 1. 188-194.

Jones. F. N.. \& Marcus. M. J. The subject effect in judgments of subjective magnitude. Journal of Experimental Psychology. 1961 . 61. 40-44.

JoNes. F. N.. \& Woskow. M. H. On the relationship between estimates of magnitude of loudness and pitch. American Journal of Psychology. 1962, 75. 669-671.

LCCE. R. D. What sort of measurement is psychophysical measurement? American Psychologist. 1972. 27. 96-106.

Macmillan. N. A.. Moschetto. C. F.. Bialostozky. F. M.. \& ENGEL. L. Size judgment: The presence of a standard increases the exponent of the power law. Perception \& Psychophysics. 1974, 16. 340-346.
Marks, L. E. On scales of sensation: Prolegomena to any future psychophysics that will be able to come forth as science. Perception \& Psychophysics. 1974. 16. 358-376.

Marks. L. E.. \& CaIN. W. S. Perception of intervals and magnitudes for three prothetic continua. Journal of Experimental Psychology, 1972. 94. 6.17.

Marks. L. E.. \& Stevens. J. C. Individual brightness functions. Perception \& Psychophysics, 1966. 1. 17-24.

Pradhan. P. L.. \& Hoffman, P. J. Effect of spacing and range of stimuli on magnitude estimation judgments. Journal of Experimental Psychologv. 1963. 66. 533-541.

Ruie. S. J. Subject differences in exponents of psychophysical power functions. Perceptual and Motor Skills, 1966, 23. $1125-1126$

RuLE. S. J. Subject differences in exponents for circle size and proportion. Perceptual and Motor Skills, 1968, 26, 520.

RULE. S. J. Subject difference in exponents from circle size. numerousness, and line length. Psychonomic Science, 1969. 15. 284.285.

Stevens. J. C.. \& Guirao, M. Individual loudness functions. Journal of the Acoustical Society of A merica, 1964, 36. 2210-2213.

Stevens. J. C.. \& Shickman, G. M. The perception of repetition rate, Journal of Experimental Psychology. 1959, 58. 433-440.

Stevens. S. S. The psychophysics of sensory function. In W. A. Rosenblith (Ed.). Sensory communication. Cambridge. Mass: M.I.T. Press. 1961.

Stevens. S. S. Neural events and the psychophysical law. Science. 1970, 170, 1043-1050.

UTtal. W. R. The psychobiology of senson coding. New York: Harper \& Row. $197 \dot{3}$.

(Received for publication March 19.1975; revision accepted September 11. 1975.) 